\title{
Job (In)Security and Workers' Training Decisions: A Framing Approach
}

\author{
Pascal Kamphuis ${ }^{\star 1}$, Arie C. Glebbeek ${ }^{2}$ \\ ${ }^{1}$ Hanze University of Applied Sciences Faculty of Law/Marian van Os Centre for \\ Entrepreneurship Postbus 70030, 9704 AA Groningen, The Netherlands \\ ${ }^{2}$ University of Groningen Department of Sociology Grote Kruisstraat 2/1, \\ 9712 TS Groningen, The Netherlands
}

Received: 07.06.2019, Accepted: 29.09.2020, Published: 09.12.2020

\begin{abstract}
Context: In this study, we attempt to contribute to the scarce evidence about the relationship between perceived labour market insecurity and worker training investments. Drawing on existing research into framing in decision-making, we investigate whether framing the labour market as insecure increases the willingness of workers to invest in training. We also investigate whether this effect is larger when training contract terms are favourable, such as when training is done mostly in an employer's time, or when no payback clause is included.

Approach: Data are gathered through a vignette-study under a sample of senior Dutch students, with experimental manipulation of frames. Respondents are given a questionnaire in which they are asked to imagine themselves working for a fictitious firm (but presented to them as real). The security/insecurity frames are elicited by randomly stressing either the positive or negative side of a series of events related to the labour market position of people working in this firm. Respondents are then asked to respond to five vignettes, each of these a randomly generated combination of training contract terms. For each vignette, respondents are asked to state whether or not they would be willing to go along with the specified training program under the conditions outlined in that vignette. Data are analysed with multilevel logistic regression.
\end{abstract}

Findings: The willingness to train is not invariably greater under an insecurity frame. Instead, we find a crucial interaction: the willingness to train is greater under an insecurity

*Corresponding author: pa.j.kamphuis@pl.hanze.nl 
frame when training-contract terms are favourable (e.g when no payback clause is included), but smaller when training-contract terms are unfavourable. Since the positive and negative effects are approximately equal in size, in a balanced design such as ours they cancel each other out, resulting in a close to zero overall effect for the frame variable.

Conclusion: Our results suggest that, when workers are aware of the insecurity in their situation, this only makes them more willing to follow training when the risk of losing their investment is low.

Keywords: VET, Vocational Education and Training, Further Training, Training Investment, Employability, Employment Security, Perception

\section{Introduction}

Can workers be brought to invest more in training when they are aware of the vulnerability of their jobs? And what role do the formal terms of the training contract play for this willingness? These are the questions we set out to investigate experimentally by use of a vignette design. As will become clear, the questions are highly relevant for implementing training policy in a context where lifelong learning is still making too little progress.

The issue of lifelong learning has been on national and international agendas for quite some time. The beginning of the international debate on lifelong learning can be traced back to the 1970s, when it became a policy priority for the Organisation for Economic Co-operation and Development [OECD] (Bengtsson, 2013). Lifelong learning is seen as all learning activities, during an individual's life, aiming to improve knowledge and competencies (Organisation for Economic Co-operation and Development [OECD], 2001, p. 10). The promotion of lifelong learning is seen as essential for countries and citizens, for example to keep up with increased digitalisation (OECD, 2019a, p.3). Accordingly, many reports have addressed the obstacles to lifelong learning and many countries adopt policy measures aimed at stimulating it (e.g. OECD, 2001, 2016; Panteia, 2019; Wetenschappelijke Raad voor het Regeringsbeleid [WRR, Scientific Council for Government Policy], 2013).

A few years ago, the Dutch Council for Education (an advisory body for the government and parliament) commissioned a study into the question "why isn't the growth rate of lifelong learning in The Netherlands higher, despite the many advisory reports addressing this matter?" The researcher who tried to answer this question found that this was not because the recommendations of those reports were not followed. Many policy measures have actually been implemented, but lifelong learning participation figures have not increased significantly as a result (Golsteyn, 2012). In 2010, 16,7\% of the population aged 25-64 had followed some form of education or training in the previous 4 weeks, which fell short of the Dutch Government's goal of 20\%. In the period 1998-2010, participation figures showed an 
increase till 2001, but remained stable after that (Golsteyn, 2012, pp. 3-4). A similar picture arises in a more recent report, for the period 2015-2017 (Maslowski, 2019, p. 16). Also the number of training activities in which Dutch adults participate over the previous 2 years seems stable over time (Maslowski, 2019, p. 18). Non-formal learning activities may of course compensate for this standstill, but although these are important, the Netherlands is not outstanding in this regard (Maslowski, 2019, p. 149). Moreover, the groups that participate the least in formal training also profit the least from informal learning (van Echtelt et al., 2016, p. 10), so both types should not be regarded as substitutes. Unsurprisingly, the Dutch Scientific Council for Government Policy characterised its country's situation with regard to lifelong learning as being in a 'deadlock' (WRR, 2013, pp. 312-315).

The issue of participation figures falling short of policy goals is not limited to the Netherlands. For example, average participation figures for the European Union seem to have stabilised around 10\% from 2005 till 2010, whereas the goal set for 2010 was 12,5\% (Golsteyn, 2012 , p. 4). Also, around $60 \%$ of adults in surveyed countries of the OECD do not participate in formal or non-formal job-related training in a given year (OECD, 2019b, p. 30).

Thus, it is clear that, despite the attention lifelong learning has received in policy circles and advisory reports for many years, reality still lags behind of what is considered necessary and desirable. This explains why a lot of research is done into training motivation (e.g. Burchert et al., 2014; Kyndt et al., 2014; Sutha et al., 2016). Dutch researchers Fouarge et al. (2013) conclude that the (lack of a) willingness to train is an autonomous factor explaining training participation. The OECD country report on the Netherlands puts it even more sharply: "(D)espite many years of talking about the importance of developing a learning culture and the introduction of a series of policy measures aimed at making it a reality, the country is still far from realising this aim, as evidenced by the low 'readiness to learn' of Dutch adults when compared with their peers in other OECD countries" (OECD, 2017, pp. 24-25).

Considering an explanation, the Social and Economic Council of the Netherlands suggested that workers (and their employers) have "an insufficient sense of urgency" of the importance to invest in their development (Sociaal-Economische Raad [SER, Social and Economic Council of the Netherlands], 2017, p. 36). Time inconsistency (efforts have to be made in the present, potential benefits lie in the distant future) is supposed to play a major role in this (Centraal Planbureau [CPB, Netherlands Bureau for Economic Policy Analysis], 2016, pp. 287-289). Elaborating on this argument, one might assume that workers often are insufficiently aware of the importance of 'training' and of 'staying up-to-date' in their profession. Once assured of a permanent job, they feel secure and cease to worry about the rapid changes in the economy and the labour market outside of their firm. Studies have shown that people are indeed often over-optimistic about things such as their own abilities, chance of entrepreneurial success, risk of accidents or disease, chance of winning lotteries, or risk of getting fired from a job (Sunstein, 1998). Sure enough, most Dutch workers on permanent 
contracts actually consider their jobs to be relatively secure (van Vuuren \& Smulders, 2018), and arguably, do therefore not experience a need to enhance their employability. This leads to the possibility that workers would be more willing to train if they were to perceive more job insecurity. To find out whether this might be true, is the aim of the present study.

Despite the plausibility of this idea, the influence of job insecurity has received very little attention in research so far. In a systematic review of 56 empirical studies, as many as 117 possible antecedents of the (intended) participation in work-related training were identified (Kyndt \& Baert, 2013). However, only two studies addressed the influence of the likelihood of losing one's job (Kyndt \& Baert, 2013, p. 289). The first study (Sanders et al., 2011) assumed that "lower educated workers with a higher level of job insecurity will be more motivated to take up training activities in order to prevent job loss" (p. 406). However, the researchers were unable to confirm this assumption in their study. In the second study, Elman and O'Rand (2002) did find a positive relation, but this concerned mostly adult education in regular educational institutions rather than training within firms.

Two other studies that we came across did not produce convincing results either. Lee et al. (2003) report that during a recession employees were more willing to undergo training (and actually spent more time undergoing training). However, their results were distorted by a very disproportional distribution of Thai respondents (who were less inclined to train) and Singaporean respondents (who were more inclined to train) during and after the recession. Van Hootegem et al. (2018) also report that job-insecure individuals are more willing to participate in both internal and external training. They are cautious about this result, however, because it was contrary to their own theoretical expectations.

A number of other studies have addressed the role of contextual factors for training investments (e.g. Evans \& Kersh, 2014; Fuller et al., 2007; Leonard et al., 2018). However, we agree with the recent conclusion of Lebert and Antal (2016), who find that "concerning the influence of perceived job and employment insecurity on participation in further training, only little evidence is available" (p. 3). One would, however, expect such a relation to exist, based on what is known about the effects of training. Findings by Bassanini (2006), based on data of 15 European countries, suggest that workplace training foremostly increases the perceived job-security of vulnerable employees. A study of Dutch panel data by Picchio and van Ours (2013) seems to confirm that participation in firm-provided training significantly improves employment prospects, also for older workers. And a more recent German panelstudy by Kohlrausch and Rasner (2014) suggests a positive effect of workplace training on perceived job security, not only in the short term, but in the long term as well. The protective effect of following training reported in the literature leads Lebert and Antal to the explicit hypothesis that "the higher the perceived employment insecurity, the more likely participation in further training" (2016, p. 5). In their Swiss study, Lebert and Antal did not find support for this hypothesis (they even found a slight association in the opposite direction). However, 
this may have been due to the fact that they looked at actual training participation. In practice, the latter depends not only on workers' willingness to train, but also on firm policy. For a strict test of the hypothesis, one would have to focus on the pure willingness to train (that is, unconfounded by practical obstacles and the co-operation of other parties).

Therefore, following Lebert and Antal, in the present study, we attempt to test their hypothesis by focusing on an unconfounded measure of the willingness to train. To do so, we study this matter in an experimental setting. We set up a vignette experiment with a framing structure, where subjects are confronted with security versus insecurity aspects of the same objective situation. The choice for framing of the same objective situation is crucial. This is because there is little interest in showing that workers' willingness to train increases when they are in an overtly insecure situation, such as when there are mass-layoffs or when firm bankruptcy is imminent. The practical relevance of such a finding is doubtful, since at that point there is not much to be rescued anymore. From a policy point of view, it is much more relevant to know if it matters for the willingness to train when people start to perceive a given situation from an insecurity perspective rather than a security perspective. In ensuing research, therefore, people should be made aware of the insecurity inherent in their normal situation, rather than be placed in a situation of overt insecurity; and this explains our choice for a framing design (see section 2.1).

To these varying (in)security frames we added another variable, namely the division of investment costs between worker and employer as stipulated in the training contract. After all, when it comes to the decision to invest in training there are several relevant aspects that employer and worker need to agree to. For instance, they will need to agree on who will carry the financial costs of the training, and in whose time training will take place. They will need to agree if and how high a wage increase will take place after training, or if there are any limitations for the worker after completion of the training, such as a pay-back clause. These are the so-called terms of the training contract. A number of studies suggest the importance of these (e.g. Künn-Nelen et al., 2018; Tuor Sartore \& Backes-Gellner, 2014). Now, an increase in the perceived urgency of training that comes with an insecurity frame might stimulate training. However, if, for example, one has to pay a large share of the cost of training oneself, it is less likely that an increase in that perceived urgency will make a difference. The reason for this is that, under an insecurity frame, there is also a perceived increased risk of getting fired. If one is fired before one is able to recoup one's investment with the current employer, there will always be some risk that one will not find a new job where the remainder of the investment can be recouped. Moreover, if one is fired before the training is concluded, one would not be able to recoup one's investment at all. Therefore, as a further application of the role of insecurity versus security framing, we will also investigate how its effect on the decision to invest in training is moderated by the terms of the training contract (see section 2.2). 


\section{Hypotheses}

\subsection{Framing: Security Versus Insecurity}

On the basis of our discussion of the literature in the previous section, our question is if it matters for the willingness to invest in training when workers perceive their labour market situation from an insecurity, rather than a security perspective. This, in turn, leads us to the question how workers could be made more aware of the insecurity of their situations.

From experimental research on framing in decision-making we know that when people focus on different aspects of the same situation, different decisions may ensue. For example, given the choice between a sure outcome and a risky option, people seem to be willing to take larger risks when options are worded in terms of avoiding losses. This is the classical framing result as first introduced by Tversky and Kahneman (Kahneman \& Tversky, 1979; Tversky \& Kahneman, 1981). Moreover, often, stressing the gains of performing an act seems less persuasive than stressing the losses of not performing it (or put differently: obtaining a good seems not as valuable as avoiding its loss) (Levin et al., 1998).

One particularly relevant kind of study of framing effects is the study of what Levin et al. (1998) deem attribute framing. These studies show that people are, for instance, more likely to evaluate gambles favourably when these are described in terms of winning rather than in terms of losing. Similarly, people are more likely to rate policies favourably when described in terms of its success rate than in terms of its failure rate. Likewise, they are more prone to rate goods favourably when the positive rather than the negative side of the same attribute is highlighted. The explanation that is given for this phenomenon is that when either the positive or negative outcomes are made salient, selective attention is promoted to only the positive or negative outcomes. This, in turn, leads people to evoke favourable or unfavourable associations (Levin et al., 1998).

In line with the general idea of framing behind such experimental studies, our idea is that the employment context which people focus on makes a difference for the decision to invest in training. Specifically, we propose that whether attention is focused on the insecurity (or volatile) aspects of the job or on the security aspects of the job makes a difference for the willingness to train. Take, for instance, lay-offs in the firm where a worker works. Attention can be focused on the percentage of workers that have left the firm during a certain period, but attention can also be focused on the (complementary) percentage of workers that are still in their jobs. ${ }^{1}$ When attention is focused on the former we expect this to make training investments seem more urgent, and when attention is focused on the latter we expect this

\footnotetext{
1 A similar perspective is taken by Vishwanath (2009), in a study on the effects of framing on the adoption of new technologies. In that study, for some participants it was, for example, highlighted that a majority of persons who tested the technology found it to be invaluable and that the technology worked well most of the time (positive frame). For other participants, it was highlighted that a minority found it to be worthless and that it failed some of the time (negative frame).
} 
to make training investments seem less urgent. Why is this? When emphasis is laid on the percentage of employees that have stayed with the firm - the security frame -, it is in fact the positive outcomes of the labour market situation that are highlighted. We therefore expect that this will promote the selective attention of workers to such positive outcomes and lead them to judge the situation more favourably. When the situation is judged more favourably in terms of labour market prospects, training investments (as a means to deal with insecurity on the labour market) will seem less urgent. Conversely, when emphasis is laid on the percentage of employees that have left the firm - the insecurity frame-, it is in fact the negative outcomes of the labour market situation that are highlighted. We therefore expect that this will promote the selective attention of workers to these negative outcomes and lead them to judge the situation less favourably. Training investments will, correspondingly, seem more urgent. A similar line of reasoning applies to, for instance, the percentage of workers leaving the firm that found a new job promptly versus the percentage of workers that did not. When workers focus on the latter, we expect them to judge the situation less favourably, making training investments seem more urgent. This reasoning is in line with the explanation Levin et al. (1998) offer for framing effects in the evaluation of objects, when the same attribute is positively or negatively formulated.

Following this reasoning, and in accordance with Sanders et al. (2011) and Lebert and Antal (2016), we state our main hypothesis:

H1: The willingness of workers to invest in training is higher when the context is framed as insecure rather than secure.

\subsection{The Moderating Role of Training Contract Terms}

When it comes to the decision to invest in training, it is the distribution of costs and risks that employer and worker need to agree about. The specific configuration of these costs and risks can be said to constitute the terms of the training contract. Based on existing literature, we have selected those provisions of a training contract we believe are the most important:

1. Who will carry the financial costs of the training. In the case of work-related training the employer may carry all financial costs associated to the training, or the costs may be differently shared by the two. Examples of such costs are programme fees, books and other study materials and travelling costs. A study by Künn-Nelen et al. (2018) suggests the importance of this factor.

2. In whose time training will take place. Work related training may be carried out in work time, or it may be spread over both the employer's and worker's time. Findings by KünnNelen et al. (2018) and by Tuor Sartore and Backes-Gellner (2014) suggest the importance of this factor. 
3. If and how high a wage increase will take place after training. Since the productivity of the worker due to the training might increase, it is possible that he receives a wage increase afterwards. In an overview of studies into the returns of training for workers given by Groot and Maassen van den Brink (1998), wage increases between 4 and 16 percent are cited, with a large variation within this range.

4. If a payback clause is included. When training concerns transferable skills, there is a risk that, after completion of the training, a worker will leave the firm to work for another firm. In such a case, the firm is unable to recoup its investment. The firm may therefore wish to implement a so-called payback arrangement. Such a payback arrangement stipulates that a worker must refund the employer with a percentage (usually decreasing over time) of the training costs incurred, if the worker prematurely leaves the firm. In the Netherlands, the arrangement is usually limited to a certain period, for example two years after completion of the training, after which it no longer applies (Arbeidsrechter, 2018). Künn-Nelen et al. (2018) found this to be a factor affecting the willingness of employers to invest in worker training. It seems plausible, however, that this will also be important for the worker's willingness to train.

The influence of these contract terms on a worker's willingness to accept a training offer is obvious and the corresponding predictions are, accordingly, somewhat trivial. Nevertheless, they can be seen as controls for the validity of our data (to exclude, for example, that questions were misunderstood, or answered in an unserious and random way). The control hypothesis thus reads:

$H$ (Control): The willingness of workers to invest in training is greater (a) the larger the share of the financial costs of training taken up by the employer; (b) the more the time spent on training is in the employer's time; (c) the higher the offered post-training wage increase; and (d) when a payback clause is not included in the training contract.

However, these training contract terms become particularly interesting when we look at how they can influence the effect of the perceived insecurity of the labour market on the willingness to train. An increase in the perceived urgency of training is expected to stimulate the willingness to train but, under this insecurity frame, there is also a perceived increased risk of getting fired. If one is fired before one is able to recoup one's investment with the current employer, there will always be some risk that one will not find a new suitable job where the remainder of the investment can be recouped. Moreover, if one is fired before the training is concluded, one would not be able to recoup one's investment at all. Now, when the worker has to pay only a small amount of the financial costs, this will most likely not be an issue. In that case we expect an uninhibited stimulating effect of the perceived insecurity on the 
willingness to train. However, if the worker has to pay a substantial amount of the costs, we expect this to make the stimulating effect of the insecurity frame smaller. A similar reasoning applies to the amount of time spent on training that is done in the worker's own time. In addition, under the insecurity frame, the perceived insecurity inside the current firm makes it attractive to leave one's current job for a more secure job if one comes along. Without a payback clause in the training contract, leaving is not a problem, and in such case we expect an uninhibited stimulating effect of the perceived insecurity on the willingness to train. With a payback clause, however, leaving voluntarily might be especially burdensome, and we expect this to make the stimulating effect of the insecurity frame smaller.

Regarding the size of the post-training wage increase, it is less clear-cut if this moderates the stimulating effect of the insecurity frame. An essential difference with the other three contract terms is that a wage increase will at its worst be zero, and this does not entail a financial investment that needs to be recouped. From this viewpoint, therefore, there is no reason to assume that the stimulating effect of the insecurity frame will be any smaller under lower wage increases than under higher wage increases.

In addition, our assumption is that the overall effect of the perceived labour market insecurity on the likelihood of training will be positive. This is because we expect that, even with unfavourable training contract terms, the effect of an increase in the perceived urgency of training on the willingness to train will still be positive (albeit smaller, as explained). This seems reasonable, since, in a context marked by general job insecurity (in- and outside the current firm), training in transferable skills, if concluded, increases one's job-chances. In fact, the choice facing a worker is that between a chance of no job at all when one opts not to train, and an increased chance of a job when one does, with some risk that the investment was in vain or brings with it a residual payback obligation. In such a situation, training would seem to be the preferable option. Moreover, as pointed out before, people are especially willing to take risks to avoid losses (Levin et al., 1998). In this consideration, training will thus still, more often than under a security frame, be seen as the most rational strategy to pursue.

This reasoning can be summarised in our second hypothesis, comprising an interaction effect:

H2: The increase in the willingness to invest in training under the insecurity frame is larger with favourable training contract terms than with unfavourable training contract terms.

As stated, we believe this interaction to hold for three of the four contract terms we included in the research. 


\section{Method}

\subsection{Research Design}

The willingness to invest in training has been the subject of numerous empirical studies, both with regard to the motivations and behaviours of the workers and/or their employers. In recent years, the method of vignettes has been introduced into this field of research (Fleischmann \& Koster, 2017; Karpinska et al., 2015; Lazazzara et al., 2013). A vignette-study (also: factorial survey or conjoint analysis) is a quasi-experimental approach in which respondents are presented different situations (the vignettes). Each of these is a randomly generated combination of characteristics which they are asked to judge. In our case, each of those situations corresponded to a specific configuration of contract terms. Our study elaborates on this approach by adding the manipulation of frames to the experimental design.

In this study, respondents were 196 senior (third and fourth year) students from two universities in The Netherlands. Respondents were given a questionnaire in which they were asked to imagine themselves working for a fictitious firm. The security/insecurity frames were elicited by randomly stressing either the positive or negative side of a series of events related to the labour market position of people working in this fictitious firm. Each respondent was then asked to respond to five vignettes, each of these a randomly generated combination of training contract terms. For each vignette, respondents were asked to state whether or not they would be willing to go along with the specified training program under the conditions outlined in that vignette. The data are analysed using multilevel logistic regression.

Asking respondents to make choices in a fictitious situation represents an important reason to opt for students rather than actual workers. Recall that we are not interested in the effect of objectively different labour market situations, but rather, in the effect of framing a given same situation as insecure versus secure. To study the effect of the insecurity/security frames these conditions have to be manipulated experimentally. An important advantage of using students is that the situation defining the frames can be presented as real, which may be important for a successful manipulation. This would be impossible for actual workers with some knowledge of their sector (about, for example, actual figures of workers that were laid off from the firm or that could not find a job soon after leaving the firm). In such case, presenting the situation as explicitly fictitious would demand from workers that they abstract from their actual situation, which might be an impossible request. Therefore, students are a good alternative, especially since most of them already have work-experience. In the Netherlands, the vast majority of students have part-time jobs next to their studies, typically in jobs requiring little educational qualifications (e.g sales-assistant, cleaning, cashier) (van der Meer $\&$ Wielers, 2001). ${ }^{2}$ Moreover, part of all the studies our respondents followed is a work place-

\footnotetext{
2 So, not in the type of job portrayed in the questionnaire (see 3.2).
} 
ment (internship) of six months or more. By picking just senior students who are about to graduate and enter the labour market, we are confident that they will have sufficient affinity with the worker role. Of course, doubts may be raised as to how representative this group is for workers in general. We cannot answer these doubts, but our theoretical predictions, if correct, should also hold for this particular group. This is in line with the view that theorytesting implies deduction from theory to experiment, rather than induction from sample to population (Willer \& Walker 2007, pp. 131-132). In the following sections, we will explain each of the aspects of our approach in more detail.

\subsection{Independent Variables}

\section{Frames}

Respondents were given a questionnaire in which they were asked to imagine themselves working for a fictitious firm. The security/insecurity frames were elicited by randomly stressing either the positive or negative side of a series of events related to the labour market position of people working in this fictitious firm. Specifically, respondents were either presented with the percentage of workers who had fared well over the last five years (security frame), or the complementary percentage of workers who had fared less well (insecurity frame). In studies on attribute framing effects, such effects seem to be less likely when dealing with extreme outcomes (e.g. extreme chances of losing or winning in a gamble) (Levin et al., 1998). Also, according to Festinger (1971), it is difficult to produce variables in an experimental setting that are strong enough to induce a measurable effect. Therefore, in order to maximise the strength of the frame variable, we opted for a construction where the percentages are approximately in a 50-50 relation to each other. To increase realism and to maximise the chance that respondents indeed adopt the frames, the frames were presented in the form of a short newspaper article about the firm, that had supposedly appeared in a national paper. The firm type was also carefully chosen to reflect the type of work that the respondents might do in the future, given their educational background. Specifically, the firm was a consultancy firm that advised organisations in the social sector on how to optimise the provision of their services (see also 3.4). Great care was taken to assure that each newspaper article described exactly the same situation, and that they only differed in the way the information was presented. ${ }^{3}$ The events chosen to define the frames were:

- Percentage of workers that have stayed with versus left the firm over a 5 year period

- Percentage of workers that have left voluntarily versus were laid off

\footnotetext{
3 The original newspaper article in Dutch and an English translation are available upon request from the authors.
} 
- Percentage of workers leaving the firm that did find versus did not find a job within six months

- Percentage of workers leaving the firm that did find versus did not find a job similar in content

- Percentage of workers leaving the firm that now earn similar or higher incomes versus lower incomes.

The resulting variable INSECURITY is a dichotomous variable measuring whether the respondent was presented the security or insecurity frame.

\section{Vignette and training contract terms}

After the newspaper article a text followed in which the respondent was told that he is working at the firm on a permanent contract and earning net monthly wages of 2000 Euros. At a certain moment he is offered to follow a training program leading to a recognised certificate, and of which the total cost (enrolment, books and other study material and travelling costs) is 2000 Euros and the required total time investment is 120 hours. Each respondent was then asked to respond to five vignettes, each of these a randomly generated combination of training contract terms. For each vignette respondents were asked to state whether or not they would be willing to go along with the specified training program under the conditions outlined in that vignette. The number of vignettes was kept low to maximise the chance that the relevant frame perspective remained active throughout the entire questionnaire. ${ }^{4}$ The following training contract terms were varied in the vignette:

- Share of costs (enrolment, books and other study material and travelling costs) taken up by the employer (COST): 25\% (€500), 50\% (€1000), 75\% (€1500);

- Share of training done in employer's time (TIME): 25\% (30 hours), 50\% (60 hours), $75 \%$ (90 hours);

- How large a wage increase will take place after training ends (WAGE): $0 \%, 2 \%, 4 \%, 6 \%$;

- Whether or not a payback clause was included (NOPAYBACK). If it was, it stipulated that $100 \%$ of the cost incurred by the employer is owed back if the worker decides to leave the firm within 2 years after completion of the training.

\footnotetext{
${ }_{4}$ An English translation of the text and of a vignette is available upon request from the authors.
} 
We can now look at how each of these contract terms is associated to the willingness to accept the training offer and how it interacts with the frame variable. Naturally, there is no guarantee that a conveyed willingness also corresponds to actual behaviour in a real-life setting, although a number of studies have shown that responses to vignettes do resemble responses to actual situations (Taylor, 2006). A major advantage of this method is, however, that we can study very specific aspects of the decision-making situation that are difficult to grasp in a retrospective survey. In the latter case, measuring instances of training decisions and of associated training contract terms, especially when training did not take place, would open the door to all kinds of memory biases and rationalisations. The vignette approach may be less prone to bias due to social desirability and also gets around the problem of collinearity between variables that comes with conventional surveys (Taylor, 2006).

Another argument in favour of the vignette approach is the fact that, in real-world labour markets, training contract terms may already be (partially) defined by collective labour agreements. This is certainly very common in the Netherlands. Collective labour agreements may, for example, contain clauses dictating how the costs and time of training should be shared between employer and worker under different circumstances, causing a 'restriction of range' of major variables. A vignette study thus allows us to study the effect of a variety of training contract terms that are perhaps not usually found in real-life settings, but that are of theoretical interest nonetheless.

\subsection{Dependent Variable}

To measure the willingness to train (TRAIN), the respondent was asked, for each vignette, whether or not he would be willing to follow training under the stated conditions. Respondents in the study stated that they were willing to follow training in 39 percent of the cases (380 out of 971 vignettes).

\subsection{Pilot, Sample and Procedure}

Respondents were senior (third and fourth year) students from two universities in The Netherlands, that were about to graduate and enter the labour market. Prior to the actual study, a pilot was carried out amongst 11 senior students (that did not follow any lectures anymore). Because there was a chance that these students would interact with the students in the actual study, and reveal the purpose of the experiment, only one frame was used. Time filling out the questionnaire was clocked and afterwards an in-depth interview with the participant was carried out. The pilot revealed a few minor ambiguities in the instructions and 
formulations of the questions, which were corrected ${ }^{5}$. For the most, instructions and formulations seemed clear and participants seemed to have no problem making the decision-task.

In the actual study, respondents were 196 senior students from two universities in The Netherlands, that were about to graduate and enter the labour market. Respondents were obtained by asking several lecturers if we could come by at one of their lectures, and ask students to fill out a questionnaire. Geographical proximity of the universities and existing contacts of the research group played an important role in this. The respondents in this convenience sample were from 15 different classes, from six different schools. Schools were chosen so that the firm and type of work portrayed in the newspaper article (see 3.2) matched the type of work the respondents might do after their study (e.g. social work, legal studies, management). For a successful frame-manipulation it is vital that respondents, when filling out the questionnaire, are not aware of the purpose. To minimise the possibility of contamination due to contact between respondents, efforts were made to administer questionnaires on the same day or at least adjacent days. Classes from the same school were always administered the questionnaire on the same day, where possible at the same time. Due to unforeseen circumstances, not all schools could be approached at the same time. To check for possible contamination due to communication between respondents, we looked at whether our results differed when only looking at those trials where contamination due to communication could be ruled out. These were the first two trials that were run parallel to each other, one trial 3 months later that was the first on that day, and three trials 5 months later that were also the first on that day and also ran parallel to each other. We found no evidence for contamination; the 'uncontaminated' trials give the same results as the 15 trials in total.

Respondents were told that the questionnaire was part of a study into training investment choices of (future) workers. The frame was communicated in a text that preceded the questionnaire. Textual, rather than oral, communication was necessary to allow random assignment to each frame, but also enabled us to avoid problems of inattention of respondents and of experimenter bias (Plutchik, 1974; Willer \& Walker, 2007). The frame text and the questionnaire were presented in two separate envelopes. Respondents were instructed to carefully read the contents of the first envelope (frame text) first and then put it back. Only then could they proceed with the second envelope (questionnaire). This was to minimise the chance that they would (partially) skip reading the frame text and go to the questionnaire straight away. It was also to avoid that neighbouring students got a good look at each other's frame texts, which might then have revealed the purpose of the experiment. As a preventive measure, both newspaper articles were in any case constructed in such a way (in terms of headings and layout) that seeing the difference between them would require quite an effort.

5 For example, for some students in the pilot it was not clear that a payback clause only applied if they themselves decided to
leave. For the final questionnaire, therefore, the formulation "if you decide to leave" was changed to "if you yourself decide to leave". 
Respondents were not de-briefed afterwards. However, the experiment did not involve sensitive matters that could in any way provoke harm. Very importantly, explicit de-briefing could have led to a greater chance of contamination due to contact between respondents. Explicit de-briefing would mean that respondents would hear what the exact purpose of the experiment was (i.e. frame them into either a security or insecurity frame), making this the object of their explicit attention. This could make it more likely that they talk about the purpose of the experiment to others, and that this information would reach people that had still to participate in the experiment.

With 196 respondents and 5 vignettes per respondent, in total 971 observations were made. All students that were approached filled out the questionnaire, but 9 vignettes were left unanswered (all spread over different respondents). In an additional 6 cases (30 vignettes) some of the control variables (section 3.6) were left unanswered. The non-response is quite small, so that it seems highly unlikely that this might have compromised the random assignment of experimental conditions (training contract terms and frames). Moreover, as expected, for the remaining 941 observations, there is essentially no correlation between the different training contract terms, between training contract terms and frames, and between these and measured background characteristics.

Regarding the adequacy of the obtained sample size, it should be noted that our design is a multilevel design, with vignettes nested within individuals (see 3.5 ahead for a more detailed explanation). In such a design, the accuracy of estimates and sufficient power to detect effects are dependent on both level 2 sample size (number of individuals) and level 1 sample size (number of vignettes per individual). Existent simulation studies suggest that our level 2 sample size is large enough, but that our level 1 sample size is on the low side (e.g. Austin, 2010; Schoeneberger, 2016). As stated before, the number of vignettes per individual was kept low on purpose, in order to maximise the chance that the frame perspective remained active throughout the entire questionnaire. However, this may have affected the accuracy of estimates and the power to detect effects, especially cross-level interaction effects (Schoeneberger, 2016).

\subsection{Analytical Strategy}

Since the vignettes might be seen as nested in individuals, there may be dependence between observations from the same individual. Ignoring this multilevel nature of the data, by carrying out conventional regression analysis, may lead to incorrect standard errors of the regression coefficients. An appropriate technique to analyse the data is therefore multilevel logistic regression (Clarke, 2008; Snijders \& Bosker, 1999). In this approach, the dependence between the answers to vignettes belonging to the same individual is explicitly taken into account. This is done by treating vignettes as so-called level 1 units, which are nested in 
individuals (the so-called level 2 units). Furthermore, the logistic variant, rather than linear regression, was called for because of the dichotomous nature of the dependent variable. Analyses were carried out in MLwin, a statistical program for analysing multilevel data. The data were analysed using the second-order penalized quasi-likelihood (PQL-2) estimation procedure. Of the standard estimation procedures available in MLwin, this procedure seems to produce the least biased estimates (Rodriguez, 2008). Since respondents are from different schools, there may also be dependence between individuals from the same school. Therefore, we also included dummy variables for the schools in the analysis. ${ }^{6}$

\subsection{Control Variables}

Due to the random assignment of vignettes and frames to respondents, effects of the training contract terms and frames should be unconfounded by other variables. However, we measured a limited number of other variables that can be thought to influence the training investment decision, since including these in the analysis might enhance the power of the statistical tests for the variables of interest (Rossi \& Anderson, 1982). The control variables are gender (a dummy variable indicating whether the respondent is FEMALE) ${ }^{7}$, year of birth (YEARBIRTH), and the extent to which one finds the kind of job described in the frame text attractive on a 4-point scale ranging from "not nice at all" to "very nice" (JOBATTRACT). The role of gender and age when it comes to following work-related training is often studied and well-known (e.g. Bassanini et al., 2005; Evertsson, 2004; Grönlund, 2012). The variable JOBATTRACT is important because liking a job might be a pre-condition for even considering investing in training. Our respondents scored the described job on average 1.35 on a scale from zero to three. As could be expected from our framing effort, they liked the job better when its security rather than its insecurity was emphasised $(r=-0.15, p=0.00)$.

\section{$4 \quad$ Results}

Table 1 contains the second-order penalized quasi-likelihood (PQL-2) estimates for the multilevel logistic regression. The contract term variables COST and TIME and WAGE have been centered, and the NOPAYBACK and INSECURITY variables have been contrast coded. This is to assure interpretability of main effects in the presence of interaction effects and to minimize non-essential collinearity between the predictors and associated interaction terms (Cohen et al., 2003).

\footnotetext{
6 Dependence at the level of the 15 classes is not very likely. In the third and fourth year, students follow mostly elective subjects and short specialisations, meaning that, in contrast to schools, classes in this stage are relatively short-lasting arrangements. An analysis with classes as level 3 units confirms this, yielding level 3 variance estimated at almost zero.

7 In the sample, $55 \%$ of respondents were female, and $45 \%$ were male. Gender was not significantly associated to the willingness to invest in training, nor did it enhance the statistical significance of the tests (see section 4 ahead).
} 
In the column under model 1 we see, firstly, that all contract term variables COST, TIME, WAGE and NOPAYBACK behave as expected and the associated coefficients are highly significant: the worker's willingness to train increases the more the employer takes up the cost of training $(b=1.23, p<0.01)$, the more the time spent on training is in the employer's time $(b=0.75, p<0.01)$, the higher the post-training wage increase $(b=1.00, p<0.01)$, and when there is no payback clause included in the training contract $(b=1.52, p<0.01)$. All this is as should be expected, and validates our control hypothesis.

However, and in contrast to our main hypothesis, the willingness to invest in training is not generally greater when the context is framed as insecure. The coefficient of the variable INSECURITY is very close to zero and far from significant $(b=0.04)$.

Under model 2 we look into how the coefficient of INSECURITY differs for different values of the variables COST, TIME, WAGE and NOPAYBACK. We add random slopes for WAGE and NOPAYBACK (random slopes for COST and TIME are excluded, because the random slope variances for these were estimated at zero), and interaction terms of INSECURITY with each of the contract variables. ${ }^{8}$ We find a statistically significant positive coefficient for the INSECURITY by NOPAYBACK interaction $(\mathrm{b}=0.94, \mathrm{p}<0.05)$, and for the INSECURITY by TIME interaction, though the latter is only significant at the 10 percent level $(\mathrm{b}=0.41, \mathrm{p}<0.10)$. We do not find indications of an INSECURITY by COST interaction, however, nor of an INSECURITY by WAGE interaction (but, as explained before, this latter interaction was theoretically also not expected). Both the INSECURITY by COST and the INSECURITY by WAGE interactions are very close to zero and not statistically significant (b $=-0.05$ and $b=0.05$, respectively).

In model 3 we add school dummies to control for possible dependence between observations at the school level. The results remain essentially the same. Enhancing the model by adding control variables FEMALE, YEARBIRTH and JOBATTRACT did not improve on the statistical significance of the tests, so, for reasons of parsimony, these are left out. ${ }^{9}$

Closer inspection of the interaction coefficients in model 3 reveals that when the training must be done mostly in one's own time, the coefficient of INSECURITY is negative with -0.44 , but when it must be done mostly in the employer's time, it is positive with 0.34 . Similarly, when a payback clause is included the coefficient of INSECURITY is - 0.48 , but when this is not the case, it is 0.38 . Apparently, INSECURITY has opposing coefficients for different values of both TIME and NOPAYBACK, resulting in a close to zero overall coefficient. Carrying out separate analyses for observations with and without a payback clause, we find mildly statistically significant coefficients for INSECURITY of $-0.46(\mathrm{p}=0.10, \mathrm{~N}=189, \mathrm{Nn}=$

\footnotetext{
8 Random slope variances of zero actually mean that they could not be estimated accurately, and it seems reasonable to assume that in this data-set they are, therefore, small enough to be left out (Twisk, 2006, p. 26). The rationale for still including all interaction terms, even though we did not find significant random slope variances for COST and TIME, is that power to detect the latter may be low (Snijders \& Bosker, 1999, p. 96).

9 Only the (positive) coefficient of JOBATTRACT was statistically significant.
} 
484) and $0.43(\mathrm{p}=0.09, \mathrm{~N}=186 \mathrm{Nn}=487)$, respectively (PQL-2 estimates for model 1 from table 1$).^{10}$

Table 1: Results Multilevel Logistic Regression for Dependent Variable TRAIN (PQL-2 Estimates)

\begin{tabular}{|c|c|c|c|c|}
\hline & Model 1 & Model 2 & Model 3 & $\begin{array}{c}\Delta \\
\text { probability } \\
\text { at mean y }\end{array}$ \\
\hline COST & $1.23^{* *}$ & $1.36^{* *}$ & $1.39^{* *}$ & 0.33 \\
\hline TIME & $0.75^{* *}$ & $0.78^{* *}$ & $0.80^{* *}$ & 0.20 \\
\hline WAGE & $1.00^{* *}$ & $1.12^{* *}$ & $1.13^{* *}$ & 0.27 \\
\hline NOPAYBACK & $1.52^{* *}$ & $1.70^{* *}$ & $1.74^{* *}$ & 0.39 \\
\hline INSECURITY & 0.04 & -0.07 & -0.05 & \\
\hline INSECURITY*COST & & -0.05 & -0.05 & \\
\hline INSECURITY*TIME & & $0.41 \dagger$ & $0.39 \dagger$ & 0.10 \\
\hline INSECURITY*WAGE & & 0.05 & 0.05 & \\
\hline INSECURITY*NOPAYBACK & & $0.94^{*}$ & $0.85^{*}$ & 0.21 \\
\hline \multicolumn{5}{|l|}{ School (reference = Management) } \\
\hline Legal & & & $-1.01^{*}$ & \\
\hline Social & & & $-0.85^{*}$ & \\
\hline Facility Management & & & -0.03 & \\
\hline Marketing & & & -0.51 & \\
\hline Other & & & $-1.14^{*}$ & \\
\hline Random intercept variance & 1.21 & 1.37 & 1.24 & \\
\hline Random slope variance WAGE & & 0.43 & 0.43 & \\
\hline Random slope variance PAYBACK & & 2.00 & 2.31 & \\
\hline
\end{tabular}

The coefficients in table 1 represent the linear relations between the independent variables and the logged odds of the probability of accepting a training offer. To make the coefficients somewhat more interpretable, in the last column we present the change in the probability of accepting a training offer associated to a 1 unit change in each of the statistically significant independent variables, at the mean of TRAIN (0.39) (Pampel, 2000). With regard to the interactions, the largest change in probability is associated with the interaction between INSECURITY and NOPAYBACK: when no payback clause is included, the increase in probability under the insecurity frame is 0.21 higher than when a payback clause is included. Again, these changes in the probability of accepting a training offer are at the mean of TRAIN, and,

\footnotetext{
${ }^{10}$ Note that by splitting up the analysis, the average number of observations per respondent drops from 5 to 2.5 . Since a lower level 1 sample size may negatively affect power in multilevel logistic regression (Schoeneberger, 2012), we might be slightly underpowered for detecting these associations.
} 
due to the non-linear relation of the independent variables to the willingness to train, they will be larger or smaller at other points.

We did some further analyses to find out whether these results could be caused by some other hidden interactions in the data. A possible candidate for this lies in the finding that INSECURITY and JOBATTRACT (the extent to which one liked the job described) are negatively correlated. People who don't like the kind of work to begin with might not care much about training, regardless of whether it seems less or more urgent. Since such dislike seems to be stimulated by the insecurity frame, this might result in a zero effect of the frame variable. We ran PQL-2 analyses to check for an INSECURITY by JOBATTRACT interaction on the willingness to train, but found no such confounding effect.

\section{Conclusion}

\subsection{Interpretation of the Results}

In this study we investigated whether framing the labour market as insecure increases the willingness of workers to invest in training, and whether this effect is larger when training contract terms are favourable. We find that when the labour market context is framed as insecure, the willingness to invest in training is greater when training contract terms are favourable (e.g. when no payback clause is included), but is smaller when training contract terms are unfavourable. Since the positive and negative effects are approximately equal in size, in a balanced design such as ours they cancel each other out, resulting in a close to zero overall effect for the frame variable.

Clearly, our main hypothesis has to be rejected. Strictly speaking, the second hypothesis is no longer relevant now, since it entails a moderation of the main effect. This conclusion might be premature, however, considering the intriguing pattern the data revealed.

Apparently, we have encountered a qualitative interaction effect instead of the more common quantitative interaction (moderation) that we had expected. In the literature, a qualitative interaction refers to the situation where the sign of the effect changes with different values of the moderator variable (in contrast to a situation where the sign remains the same) (e.g. Bayman et al., 2010). If the positive and negative effects are approximately equal in size, and the observations are evenly spread over the categories of the moderator variable, a qualitative interaction will lead to a close to zero overall effect of the main variable. In our experiment, these conditions clearly apply.

Substantively, this suggests that perceived labour market insecurity is not irrelevant for the worker's willingness to engage in training. Its relevance is embedded, however, in the kind of reasoning that has led to our second hypothesis. The perceived insecurity stimula- 
tes the worker's willingness to invest in training when the risk to him is small, but actually deters him when that risk is large. This explains why the insecurity frame was associated to a greater willingness to train for favourable contract terms, and to a smaller willingness to train for unfavourable contract terms. We found this interaction for two of the three contract terms where this reasoning applies. As expected, it was not found for the fourth contract term ('wage increase') where the reasoning did not make sense. All in all, we believe human capital theory's standard investment logic can account fairly well for these results, provided the risk distribution is added to the cost-benefit calculus. If a worker thinks that he might lose his job (the insecurity frame), then a training investment becomes more attractive when the employer carries the costs. However, it becomes less attractive when the worker himself has to carry the costs, because in a situation of insecurity he runs a greater risk of losing his investment (cf. Greenhalgh \& Mavrotas, 1994).

Recent literature suggests yet another explanation, founded in organisational psychology, that can be seen as complementary to the economic case. This explanation is based on social exchange theory. Within firms, an exchange takes place between the commitment of workers to the organisation and the organisational support offered to them by the employer. This makes it possible for a relationship based on reciprocity to emerge, in which the positive gesture of one party is answered with a positive action from the other. In the literature on training, this theory is used to explain why employers actually invest in general training of workers, despite the risk that the latter will (threaten to) leave for another employer after completion of the training. Employers invest in such general training if they expect reciprocity from the workers (Fleischmann \& Koster, 2017; Kampkötter \& Marggraf, 2015; Leuven et al., 2005). Conversely, workers will be more inclined to commit to training if they perceive that the employer supports them in this (Kyndt \& Baert, 2013; Sanders et al., 2011; Sutha et al., 2016). This organisational support plays a central part in Sutha et al's (2016) 'integrated theoretical model' aimed at explaining the willingness of workers to participate in non-mandatory training: "The considerate and positive treatment received from the company creates feelings of gratitude in the employee's minds; this is likely to instill in them an attitude of loyalty and a sense of obligation ... that will encourage them to put in greater effort into gaining new knowledge from both mandatory as well as non-mandatory training programs" (2016, p. 142). Needless to say, this is a precarious relationship, especially if the workers already experience their position as insecure (as is the case in our experiment). They will, thus, be extra alert to signals conveying whether a reciprocal relationship exists or is being proposed. In this regard, contract terms stand out as a very clear and unambiguous signal. An employer offering favourable training contract terms in a situation of insecurity will elicit feelings of loyalty and obligation; an employer offering unfavourable training contract terms will, on the other hand, emit a clearly negative relational signal. 


\subsection{The Framing Approach}

The failure of our main hypothesis led us to consider some probable causes. The most likely cause would be that the manipulation we tried to accomplish with the frames was simply not effective; that is, respondents given the security frame text did not interpret the situation depicted any differently than respondents given the insecurity frame text. This cannot explain, however, why we did find the interactions as reported. It can neither explain the correlation with the job attractiveness we mentioned (section 3.6). Apparently, the manipulation did seem to work, because respondents under the (randomly assigned) insecurity frame found the type of work on average less attractive than those under the security frame. This is in line with our theory, which states that, under the insecurity frame, the negative aspects of the labour market situation are highlighted, promoting the selective attention of workers to these negative aspects. This, in turn, leads them to judge the situation less favourably. Clearly, this is what they did with regard to the attractiveness of the job.

In sum, although our main hypothesis was not confirmed, we conclude that our manipulation of frames seems to have been quite successful. We find support for the idea that security and insecurity trigger distinct response patterns and that the details of the training contract play an interesting and important role herein. Of course, our results might have been different if we had opted for confronting the respondents with straightforwardly different conditions (instead of different perceptions of the same conditions, i.c. frames). An example would be one situation where the fictitious firm could still make a profit, while in the other situation it might be in deep trouble. Perhaps, with such blatant insecurity, workers would be prepared to take more risks in order to enhance their employability. However, such a finding would be less interesting. That people wake up in times of emergency is fine, but from the viewpoint of labour market policy it would be preferable if they did so before it were (almost) too late. Therefore, our framing approach is more representative for the ordinary policies of trying to make workers more aware of the uncertainties of their employment.

\subsection{Limitations}

One important limitation of this study lies in the fact that respondents were senior university students. As argued, the choice for students had the advantage of making it possible to present the frames as real, which may be important for successful frame manipulation. This would not be possible for workers with some knowledge of the labour market situation in their sector. Moreover, respondents were not far from entering the labour market and very likely to already have work experience. However, the results are not necessarily representative of the behaviour of actual workers. A challenge for future research focusing on actual workers is, therefore, to get workers to abstract from their actual situation, and achieve a 
successful manipulation into fictitious frames. Correspondingly, our conclusion, to which we now turn, should, at least for the time being, be seen as a tentative one.

\subsection{Conclusion}

As we already pointed out in the Introduction, the scarce research into the role of job insecurity has yielded contradictory results. For example, Sanders et al. (2011) were unable to confirm that a higher level of job insecurity is associated to a higher motivation to train. Similarly, Lebert and Antal (2016) could not confirm that a higher perceived employment insecurity was associated to a greater likelihood of training, even finding a slight association in the other direction. On the other hand, van Hootegem et al. (2018) did find that job insecure individuals were more likely to follow training, but this was contrary to their own theoretical expectations.

Now, our own results provide an explanation for this. The effect of insecurity is empirically unstable, because it interacts strongly with circumstances; in our case, the terms of the training contract.

The existing literature even gives us reasons to expect such an interaction. Van Hootegem et al. (2018) discuss, in the context of the Conservation of Resources theory, two tenets that lead to contradictory predictions for the effect of job insecurity. Based on the 'resource acquisition tenet', investing in training would actually be an instrumental activity for workers in a situation of insecurity. The 'resource conservation tenet', on the other hand, predicts that workers in an insecure situation become less active, because they need to employ all their mental capacity to survive in such a situation. The authors were more inclined to the latter prediction (which was then not supported in their study). Given the stated ambiguity, however, such a prediction was not a very convincing one. According to an influential conceptual framework in evaluation research (Pawson \& Tilley, 1997), especially in a situation where two forces operate against each other, it is usually a third contextual factor that is decisive.

Continuing in this line of thought, this brings us to a conclusion regarding the point of departure of our own study. Will workers be more willing to follow training if they are aware of the insecurity in their situation? The answer to this must be a qualified negative: No, in itself that is insufficient. Our findings suggest that workers can be made more willing to follow training if they are made more aware of the insecurity in their situation and if training contract terms are favourable to them. So, in the end, the motivation for training appears to depend on a classical industrial relations variable: the division of risks between employer and worker. 


\section{References}

Arbeidsrechter. (2018). Opleidingen [Training]. https://www. arbeidsrechter.nl/Opleidingen-werknemers-personeel-werkgever

Austin, P. (2010). Estimating multilevel logistic regression models when the number of clusters is low: A comparison of different statistical software procedures. The International Journal of Biostatistics, 6(1), Article 16. https://doi.org/10.2202/1557-4679.1195

Bassanini, A. (2006). Training, wages and employment security: an empirical analysis on European data. Applied Economics Letters, 13, 523-527. https://doi.org/10.1080/13504850500400447

Bassanini, A., Booth, A., Brunello, G., de Paola, M., \& Leuven, E. (2005). Workplace training in Europe (IZA Discussion Paper 1640). IZA. https://www.iza.org/publications/dp/1640/workplace-training-in-europe

Bayman, E., Chaloner, K., \& Cowles, M. (2010). Detecting qualitative interaction: a Bayesian approach. Statistics in Medicine, 29(4), 455-463. https://doi.org/10.1002/sim.3787

Bengtsson, J. (2013). National strategies for implementing lifelong learning (LLL) - the gap between policy and reality: An international perspective. International Review of Education, 59, 343-352. https://doi.org/10.1007/s11159-013-9362-4

Burchert, J., Hoeve, A., \& Kämäräinen, P. (2014). Interactive research on innovations in vocational education and training (VET): Lessons from Dutch and German cases. International Journal for Research in Vocational Education and Training, 1(2), 143-160. https://doi.org/10.13152/IJRVET.1.2.4

Clarke, P. (2008). When can group level clustering be ignored? Multilevel models versus single-level models with sparse data. Journal of Epidemiology and Community Health, 62, 752-758. https://doi. org/10.1136/jech.2007.060798

Cohen, J., Cohen, P., West, S., \& Aiken, L. (2003). Applied multiple regression/correlation analysis for the behavioural sciences. Routledge. https://doi.org/10.4324/9780203774441

Centraal Planbureau. (2016). Kansrijk onderwijsbeleid. https://www.cpb.nl/publicatie/kansrijk-onderwijsbeleid

Elman, C., \& O'Rand, A. (2002). Perceived job insecurity and entry into work-related education and training among adult workers. Social Science Research, 31, 49-76. https://doi.org/10.1006/ ssre.2001.0718

Evans, K., \& Kersh, N. (2014). Training and workplace learning. In K. Kraiger, J. Passmore, N. Rebelo dos Santos \& S. Malvezzi (Eds.), The Wiley handbook of the psychology of training, development, and performance improvement (pp. 50-67). John Wiley \& Sons. https://doi.org/10.1002/9781118736982. ch4

Evertsson, M. (2004). Formal on-the-job training: a gender-typed experience and wage related advantage? European Sociological Review, 20(1), 79-94. https://doi.org/10.1093/esr/20.1.79

Festinger, L. (1971). Laboratory experiments. In W. Evan (Ed.), Organizational experiments: Laboratory and field research (pp. 9-24). Harper \& Row.

Fleischmann, M., \& Koster, F. (2017). Older workers and employer-provided training in the Netherlands: a vignette study. Ageing \& Society, 1-24. https://doi.org/10.1017/S0144686X17000356.

Fouarge, D., Schils, T., \& De Grip, A. (2013). Why do low-educated workers invest less in further training? Applied Economics, 45(18), 2587-2601. https://doi.org/10.1080/00036846.2013.780413 
Fuller, A., Unwin, L., Felstead, A., Jewson, N., \& Kakavelakis, K. (2007). Creating and using knowledge: an analysis of the differentiated nature of workplace learning environments. British Educational Research Journal, 33(5), 743-759. https://doi.org/10.1080/01411920701582397

Golsteyn, B. (2012). Waarom groeit leven lang leren in Nederland niet sterker ondanks de vele adviezen erover? [Why isn't the growth rate of lifelong learning in The Netherlands higher, despite the many advisory reports?]. University of Maastricht. https://www.onderwijsraad.nl/publicaties/rapporten/2012/06/26/studie-waarom-groeit-leven-lang-leren-in-nederland-niet-sterker

Greenhalgh, C., \& Mavrotas, G. (1994). The role of career aspirations and financial constraints in individual access to vocational training. Oxford Economic Papers, 46, 579-604. https://doi.org/10.1093/ oxfordjournals.oep.a042149

Grönlund, A. (2012). On-the-job training - A mechanism for segregation? Examining the relationship between gender, occupation, and on-the-job training investments. European Sociological Review, 28(3), 408-420. https://doi.org/10.1093/esr/jcr007

Groot, W., \& Maassen van den Brink, H. (1998). Bedrijfsopleidingen: wie neemt er aan deel en wat levert het op? [Training: who participates in it and what is its return?]. Maandschrift Economie, 62, $28-40$.

Kahneman, D., \& Tversky, A. (1979). Prospect theory: an analysis of decision under risk. Econometrica, 47(2), 263-292. https://doi.org/10.2307/1914185

Kampkötter, P., \& Marggraf, K. (2015). Do employees reciprocate to intra-firm trainings? An analysis of absenteeism and turnover rates. The International Journal of Human Resource Management, 26(22), 2888-2907. https://doi.org/10.1080/09585192.2015.1005655

Karpinska, K., Henkens, K., Schippers, J., \& Wang, M. (2015). Training opportunities for older workers in the Netherlands: a vignette study. Research in Social Stratification and Mobility, 41, 103-112. https://doi.org/10.1016/j.rssm.2015.03.002

Kohlrausch, B., \& Rasner, A. (2014). Workplace training in Germany and its impact on subjective job security: Short- or long-term returns? Journal of European Social Policy, 24(4), 337-350. https:// doi.org/10.1177\%2F0958928714538216

Kyndt, E., \& Baert, H. (2013). Antecedents of employees' involvement in work-related learning: a systematic review. Review of Educational Research, 83(2), 273-313. https://doi. org/10.3102\%2F0034654313478021

Kyndt, E., Onghena, P., Smet, K., \& Dochy, F. (2014). Employees' willingness to participate in workrelated learning: a multilevel analysis of employees' learning intentions. International Journal for Educational and Vocational Guidance, 14, 309-327. https://doi.org/10.1007/s10775-014-9272-4

Künn-Nelen, A., Poulissen, D., van Eldert, P., Fouarge, D., \& de Grip, A. (2018). Leren onder werkenden met een kwetsbare positie op de arbeidsmarkt [Learning amongst workers with a weak labour market position] (ROA Reports 5). ROA. https://cris.maastrichtuniversity.nl/en/publications/ leren-onder-werkenden-met-een-kwetsbare-positie-op-de-arbeidsmark

Lazazzara, A., Karpinska, K., \& Henkens, K. (2013). What factors influence training opportunities for older workers? Three factorial surveys exploring the attitudes of HR professionals. The International Journal of Human Resource Management, 24(11), 2154-2172. https://doi.org/10.1080/095851 92.2012.725077

Lebert, F., \& Antal, E. (2016). Reducing employment insecurity: Further training and the role of the family context. Sage Open, 6(4), 1-17. https://doi.org/10.1177/2158244016671769 
Lee, S-H., Phan, P., \& Tan, G. (2003). Impact of the Asian economic crisis on training intentions and outcomes. Human Resource Management Review, 13, 467-486. https://doi.org/10.1016/S10534822(03)00046-9

Leonard, P. Fuller, A., \& Unwin, L. (2018). A new start? Negotiations of age and chrononormativity by older apprentices in England. Ageing \& Society, 38, 1667-1692. https://doi.org/10.1017/ S0144686X17000204

Leuven, E., Oosterbeek, H., Sloof, R., \& van Klaveren, C. (2005). Worker reciprocity and employer investment in training. Economica, 72, 137-149. https://doi.org/10.1111/j.0013-0427.2005.00405.x

Levin, I., Schneider, S., \& Gaeth, G. (1998). All frames are not created equal: a typology and critical analysis of framing effects. Organizational Behavior and Human Decision Processes, 76(2), 149188. https://doi.org/10.1006/obhd.1998.2804

Maslowski, R. (2019). Grenzen aan een leven lang leren [Limits to lifelong learning]. Sociaal en Cultureel Planbureau. https:/www.scp.nl/publicaties/publicaties/2019/05/22/grenzen-aan-een-levenlang-leren

Organisation for Economic Co-operation and Development. (2001). Education policy analysis. https:// www.oecd-ilibrary.org/docserver/epa-2001-en.pdf?expires $=1576843995 \& \mathrm{id}=\mathrm{id} \&$ accname $=$ ocid5 3022830\&checksum =1722252CB021F74BB577A1E4D91DE3EE

Organisation for Economic Co-operation and Development. (2016). Enhancing employability: Report prepared for the G20 Employment Working Group. https://www.oecd.org/g20/topics/employmentand-social-policy/Enhancing-Employability-G20-Report-2016.pdf

Organisation for Economic Co-operation and Development. (2017). OECD Skills strategy diagnostic report: The Netherlands. https://read.oecd-ilibrary.org/education/oecd-skills-strategy-diagnosticreport-the-netherlands-2017_9789264287655-en\#page1

Organisation for Economic Co-operation and Development. (2019a). OECD Skills outlook 2019: Thriving in a digital world. https://www.oecd-ilibrary.org/education/oecd-skills-outlook-2019_ df80bc12-en

Organisation for Economic Co-operation and Development. (2019b). Getting skills right: Future-ready adult learning systems. https://www.oecd-ilibrary.org/education/getting-skills-right-future-readyadult-learning-systems_9789264311756-en

Pampel, F. (2000). Logistic regression: a primer. Sage Publications. https://dx.doi. org/10.4135/9781412984805

Panteia. (2019). Belemmeringen leven lang ontwikkelen [Obstacles to lifelong development]. https:// www.tweedekamer.nl/sites/default/files/atoms/files/panteia_c12300_eindrapport_belemmeringen_levenlang_ontwikkelen_def_002.pdf

Pawson, R., \& Tilley, N. (1997). Realistic evaluation. Sage.

Picchio, M., \& van Ours, J. C. (2013). Retaining through training even for older workers. Economics of Education Review, 32, 29-48. https://doi.org/10.1016/j.econedurev.2012.08.004

Plutchik, R. (1974). Foundations of experimental research. Harper \& Row.

Rodríguez, G. (2008). Multilevel generalized linear models. In J. de Leeuw and E. Meijer (Eds.), Handbook of multilevel analysis (pp. 335-376). Springer. https://doi.org/10.1007/978-0-387-73186-5_9

Rossi, P., \& Anderson, A. (1982). The factorial survey approach: An introduction. In P. Rossi \& S. Nock (Eds.), Measuring social judgments (pp. 1-25). Sage Publications. 
Sanders, J., Oomens, S., Blonk, R. W. B., \& Hazelzet, A. (2011). Explaining lower educated workers' training intentions. Journal of Workplace Learning, 23(6), 402-416. https:/doi. org/10.1108/13665621111154412

Schoeneberger, J. (2012). The impact of sample size, prevalence, estimation method and other factors when estimating multilevel logistic models [Doctoral Dissertation, University of South Carolina]. https://scholarcommons.sc.edu/etd/1036/

Schoeneberger, J. (2016). The impact of sample size and other factors when estimating multilevel logistic models. The Journal of Experimental Education, 84(2), 373-397. https://doi.org/10.1080/002 20973.2015.1027805

Sociaal-Economische Raad. (2017). Leren en ontwikkelen tijdens de loopbaan: Een richtinggevend advies [Learning and development during careers: a guiding advisory report]. https://www.ser.nl/-/ media/ser/downloads/adviezen/2017/leren-ontwikkelen-loopbaan.pdf

Snijders, T., \& Bosker, R. (1999). Multilevel analysis: an introduction to basic and advanced multilevel modeling. Sage Publications.

Sunstein, C. (1998). Selective fatalism. The Journal of Legal Studies, 27(2), 799-823. https:/doi. org/10.1086/468043

Sutha, J., Kailasapathy, P., \& Jayakody, J. (2016). Integrated theoretical model for employees' intention to participate in non-mandatory trainings. International Journal of Business and Management, 11(11), 139-155. https://doi.org/10.5539/ijbm.v11n11p139

Taylor, B. (2006). Factorial surveys: using vignettes to study professional judgement. The British Journal of Social Work, 36, 1187-1207. https://doi.org/10.1093/bjsw/bch345

Tuor Sartore, S., \& Backes-Gellner, U. (2014). Employer-supported training as a non-wage compensation component. Die Betriebswirtschaft, 74(2), 87-105. http://www.dbwnet.de/files/hefte/2014/2_2014/DBW_2_2014.pdf

Tversky, A., \& Kahneman, D. (1981). The framing of decisions and the psychology of choice. Science, 211(4481), 453-458. https://psycnet.apa.org/doi/10.1126/science.7455683

Twisk, J. (2006). Applied multilevel analysis. Cambridge University Press. https://doi.org/10.1017/ CBO9780511610806

van der Meer, P., \& Wielers, R. (2001). The increased labour market participation of Dutch students. Work, Employment and Society, 15(1), 55-71. https://doi.org/10.1177/09500170122118779

van Echtelt, P., Croezen, S., Vlasblom, J. D., \& de Voogd-Hamelink, M. (2016). Aanbod van arbeid 2016 [Supply of labour 2016]. Sociaal en Cultureel Planbureau. https://www.scp.nl/publicaties/publicaties/2016/08/30/aanbod-van-arbeid-2016

van Hootegem, A., de Witte, H., de Cuyper, N. \& Vander Elst, T. (2018). Job insecurity and the willingness to undertake training: the moderating role of perceived employability. Journal of Career Development, 1-15. https://doi.org/10.1177/0894845318763893

van Vuuren, T. \& Smulders, P. (2018). Baanonzekerheid en duurzame inzetbaarheid van werknemers en zelfstandigen. Tijdschrift voor Arbeidsvraagstukken, 34(2), 170-186.

Vishwanath, A. (2009). From belief importance to intention: the impact of framing on technology adoption. Communication Monographs, 76(2), 177-206. https://doi.org/10.1080/03637750902828438

Willer, D., \& Walker, H. (2007). Building experiments: Testing social theory. Stanford University Press.

Wetenschappelijke Raad voor het Regeringsbeleid (2013). Naar een lerende economie [Towards a learning economy]. https://www.wrr.nl/publicaties/rapporten/2013/11/04/naar-een-lerende-economie. 


\section{Biographical Notes}

Pascal Kamphuis is a lecturer in social science research methodology and researcher at the Hanze University of Applied Sciences, Faculty of Law/Marian van Os Centre for Entrepreneurship, in Groningen, The Netherlands. His research interests include multilevel statistical modelling, determinants of training investments and framing in decision-making.

Arie C. Glebbeek is an Associate Professor at the University of Groningen, Department of Sociology, in The Netherlands. His research interests include the sociology of work, public policy, and social welfare. A central theme in his work is the relationship between education and the labour market. From 2002 till 2016 he was a board member of the Dutch Sociological Association. 